\title{
BMJ Open Trajectories of success and/or distress: protocol for an observational cohort study investigating changing psychological distress among emerging Ecuadorian adults over a year
}

\author{
Clara Paz (1) , ${ }^{1}$ Gabriel Osejo-Taco, ${ }^{1}$ Chris Evans ${ }^{1,2}$
}

To cite: Paz C, Osejo-Taco G, Evans C. Trajectories of success and/or distress: protocol for an observational cohort study investigating changing psychological distress among emerging Ecuadorian adults over a year. BMJ Open 2021;11:e056361. doi:10.1136/ bmjopen-2021-056361

- Prepublication history for this paper is available online. To view these files, please visit the journal online (http://dx.doi org/10.1136/bmjopen-2021056361).

Received 11 August 2021 Accepted 12 November 2021

Check for updates

(c) Author(s) (or their employer(s)) 2021. Re-use permitted under CC BY-NC. No commercial re-use. See rights and permissions. Published by BMJ.

${ }^{1}$ Escuela de Psicología y Educación, Universidad de Las Américas, Quito, Ecuador

${ }^{2}$ Department of Psychology, The University of Sheffield, Sheffield, UK

Correspondence to

Dr Clara Paz;

clara.paz@udla.edu.ec

\section{ABSTRACT}

Introduction Emerging adulthood is a period of instability with changes in personal relationships and often a series of job changes before life trajectories clarify and more lasting decisions are possible. These changes often produce distress, and they might explain why most of the symptoms that impact the individual's mental health throughout their lives appear at this stage, although full-blown disorders are often only diagnosed subsequently. The objective of this study is to analyse the intraindividual changes in psychological distress and health-related quality of life in both student and non-student emerging adults over 1 year. Betweenindividual differences in variability will be analysed and life events will be recorded to identify possible associations.

Methods and analysis Participants will be emerging adults (18-29 years of age) students and nonstudents. The primary outcome will be psychological distress measured using the Clinical Outcomes in Routine Evaluation-Outcome Measure and the secondary outcome will be health-related quality of life measured by the EuroQol five-dimension-three-level. Sociodemographic and life events will be recorded. Information will be collected using an online survey. Analyses, described in a data analysis plan with the registration, will check the psychometric properties of the measures, describe the distribution of scores on the outcome measures, their relationship to group and other demographic variables and how they change over the seven assessment points across a year and explore any relationship between scores and life events.

Ethics and dissemination This study received ethical approval by the Comité de Ética y Bioética (Ethics and Bioethics Committee) of the Universidad de Las Américas, Quito-Ecuador (2020-0807). Results will be published in peer-reviewed journals and presented at relevant meetings. Brief reports of these publications will be disseminated using social media to reach the community and private or public organisations interested in emerging adults.

Trial registration number NCT04596345
Strengths and limitations of this study

- This is the first study tracking psychological distress and health-related quality of life in a group of emerging adults (students and non-students) across a year.

- Life events will be recorded to explore links with changes in psychological distress and healthrelated quality of life.

- Temporal variability in the outcome variables across occasions will be analysed for individual differences and comparing student versus non-student variability.

- The primary limitation will be attrition. We plan to send several reminders to the participants in each assessment point to mitigate data loss.

\section{INTRODUCTION}

Emerging adulthood has been defined as the developmental stage between 18 and 29 years of age. ${ }^{1}$ During this stage, individuals generally define their professional future, their potential route to success, and they do it either by education, employment or by combining both. ${ }^{2}$ Instability is frequent during this stage, with relationship breakups and job changes before most individuals consolidate their trajectories and make lasting choices. The turbulence of this period may explain why most of the mental health symptoms appear in this life stage, although psychiatric disorders are diagnosed later in life. ${ }^{3}$ Despite that later emergence, epidemiological evidence is that this stage is still marked by very high rates of mental health disorders, neurological problems and substance abuse. ${ }^{4}$

In industrialised societies the base of the economy has changed from manufacturing to service industries, this new situation requires trained people with tertiary education. For that reason the enrolment rate in 
this type of education has passed $50 \%$ in the population between 18 and 24 years. ${ }^{5}$ Given the increasing number of emerging adults in university and the easy access to them for researchers, the mental health of students has been widely studied. In the USA, data collected between 2016 and 2017 indicated that around 39\% of university students suffer difficulties related to their mental health, particularly depression, generalised anxiety and eating disorders. ${ }^{6}$ A study in eight countries (Australia, Belgium, Germany, Mexico, Northern Ireland, South Africa, Spain and USA) showed that around $31 \%$ of the undergraduate students acknowledged having had a mental disorder in the previous 12 months and $35 \%$ acknowledged ever having done so. ${ }^{7}$ These results are markedly higher than typical general population rates of around 13\% having, or having had, a mental disorder or difficulty with substance abuse. 8

The high prevalence of mental disorders in the student population might be explained by academic and social pressures that these individuals face every day. ${ }^{9}$ There is evidence that the distress experienced by this population is not static but fluctuates over time. A study conducted in the USA by Conley et $a l,{ }^{10}$ which followed the psychological adjustment of undergraduate students precollege and during the 4 years that it takes to get a degree, showed that psychological functioning deteriorated in the first 2 years in college when compared with the scores before starting university. Similar results were reported by Garett $e t a l^{11}$ who assessed changes in stress during the first term of first year university students. They found that stress peaks were concentrated in the academic evaluation periods and were associated with impaired sleep quality and a greater presence of negative emotions such as anger and fear.

The literature has clearly shown a high prevalence of mental disorders during the university years. ${ }^{712}$ However, longitudinal follow-up studies are scarce ${ }^{10} 11$ and the paucity of studies of young people of similar age not involved in university education leave open questions of whether distress also affects non-student population similarly and whether it is related to possibly higher stress in the student population.

\section{Study aims}

This study seeks to understand the possible psychological distress experienced by emerging adults in Quito, Ecuador and to measure within individual variation in distress across 1 year. For this purpose, we will collect information about psychological distress experienced by individuals of this age group every 2 months for a year: seven assessment points from baseline to the last assessment. Most literature about this age group is about college students and information about psychological distress in non-student populations is limited. This study aims to address this limitation by inviting participation from both populations: students and non-students. We will explore how baseline scores and score change relate to sample and other sociodemographic variables. In addition, we will explore change over time, individual differences in change and how change may relate to self-chosen and rated life events.

\section{METHODS AND ANALYSIS \\ Study design}

This is an observational cohort study. The study will be conducted in Quito, Ecuador.

\section{Participants}

Participants will be emerging adults (18-29 years old) from two population groups: students and non-students. Participants must be living in Quito, Ecuador and have competence to read and understand Spanish. Participation will be voluntary and no monetary incentives will be offered. For the student group, participants must be enrolled in a university programme (undergraduate or graduate). We will recruit this group by sending invitations to participate using the institutional email of one university in Ecuador. For the non-studentgroup participants should not be enrolled in any formal education programme (elementary, high school, undergraduate or graduate programmes) at baseline. Opportunistic sampling will be carried out to recruit this group by inviting student participants to pass on a short invite to at least one non-student participant. This type of sampling was chosen because there is no research access to the population registries in Ecuador.

This is a novel exploratory study and primarily descriptive, not null hypothesis testing. However, a priori sample size calculation considered the presence of a small effect size $(\mathrm{d}=0.2)$ for a simple baseline mean difference between the two groups (students and non-students), that indicated that 394 participants in each group gives statistical power of 0.8 for a two-tailed t-test. Samples of 60 participants, each completing the seven assessment points, will provide enough statistical power to find population difference effect sizes of 0.7 and 8 power of 0.8 to detect population correlations among variables above 0.33 .

Given that longitudinal studies usually have substantial attrition we will try to collect a baseline sample of at least 400 participants in each group. We are aware that participants' studying status might vary and change across 1 year, for that reason, status will be recorded in every assessment. Recruitment started on 15 October 2020, and it will end up in February 2022.

\section{Public involvement}

Public from the target population were involved to ensure that the questions included in the survey were understandable and likely to address the presence of psychological distress in emerging adults. We intend to disseminate the main results of this study to participants and to the public via social media.

\section{Outcome measures}

Primary

The Clinical Outcomes in Routine Evaluation-Outcome Measure $(\mathrm{CORE}-\mathrm{OM})^{13}$ is a 34 -item self-report measure 
that assesses psychological distress across four domains: subjective well-being (four items), problems and, or symptoms (twelve items), life function (twelve items)and risk to self and others (six items). Higher scores indicate higher psychological distress. It is a copyleft measure that can be downloaded from: https://wwwcoresystemtrustorguk/. The CORE-OM was translated to Spanish in Spain $^{14}$ but a psychometric exploration was conducted in Ecuador, showing good psychometric properties in college students and a non-student general population sample. ${ }^{15}$

\section{Secondary}

The EuroQol five-dimension-three-level (EQ-5D-3L) ${ }^{16}$ is a 5-item self-report measure of health-related quality of life states in adults, considering five dimensions (Mobility, SelfCare, Usual Activities, Pain and Discomfort, Anxiety and Depression), each of which has three severity levels that are described by statements appropriate to that dimension. There are normative data for the scores of this questionnaire for the Ecuadorian population. ${ }^{17}$ The EuroQol Visual Analogue Scales (EQ-VAS) will be included in the assessment, this scale is usually presented in companion of the EQ-5D-3L, and it is used as a quantitative measure of person's perception of health. The EQ-VAS presents a vertical line with two endpoints that range from $0=$ 'Worst imaginable health state' to $100=$ 'Best imaginable health state' the participant will be asked to put a mark in the line to report his or her health state.

The What's Going On? (WGO) questionnaire is a selfreport measure designed to identify life events. The individual is invited to think about three events occurred in the last 2 months, each event is then rated for impact on the individual's life. The measure has been used in the UK in a six measurement occasion cohort study of a school student sample and showed cross-lagged correlation from scores to distress scores (results in preparation, available on request).

\section{Sociodemographic information}

General sociodemographic variables such as gender, age, occupation, employment, change in student/non-student status, education, housing status, level of economic independence, caregiver responsibilities, relevant medical issues and lifestyle information will be recorded.

\section{Data collection and data management}

Participants will be invited to participate through social media and institutional email (for the student group). Potential participants will receive a link which will direct them to a screen providing information about the study and asking the consent to participate in the study. All the participants must provide informed consent before starting their voluntary participation in the study. Participants will have knowledge that they will be contacted six times after they complete the first assessment, and that the contact information will be used only for that purpose. Contact information will be deleted from the databases

\begin{tabular}{|c|c|c|}
\hline Assessment & Time & $\begin{array}{l}\text { Information to collect } \\
\text { and outcomes }\end{array}$ \\
\hline First: baseline & Time 0 & $\begin{array}{l}\text { Sociodemographic } \\
\text { information } \\
\text { Academic (student group } \\
\text { only) } \\
\text { CORE-OM } \\
\text { EQ-5D-3L } \\
\text { EQ-5D-3L-VAS } \\
\text { WGO }\end{array}$ \\
\hline Second & $\begin{array}{l}\text { Time } 0+60 \\
\text { days }\end{array}$ & $\begin{array}{l}\text { Change in } \\
\text { sociodemographic } \\
\text { information } \\
\text { CORE-OM } \\
\text { EQ-5D-3L } \\
\text { EQ-5D-3L-VAS } \\
\text { WGO }\end{array}$ \\
\hline Third & $\begin{array}{l}\text { Time } 0+120 \\
\text { days }\end{array}$ & Same as second \\
\hline Fourth & $\begin{array}{l}\text { Time } 0+180 \\
\text { days }\end{array}$ & Same as second \\
\hline Fifth & $\begin{array}{l}\text { Time } 0+240 \\
\text { days }\end{array}$ & Same as second \\
\hline Sixth & $\begin{array}{l}\text { Time } 0+300 \\
\text { days }\end{array}$ & Same as second \\
\hline Seventh & $\begin{array}{l}\text { Time } 0+360 \\
\text { days }\end{array}$ & Same as second \\
\hline
\end{tabular}

CORE-OM, Clinical Outcomes in Routine Evaluation-Outcome Measure; EQ-5D-3L, EuroQol five-dimension-three-level; EQ-5D3L-VAS, EuroQol five-dimension-three-level Visual Analogue Scale; WGO, The What's Going On.

once the participant completes the seventh assessment or if she or he decides not to continue participating in the study.

People opting to proceed with the study will be asked to complete sociodemographic information, academic information (student group), CORE-OM items, EQ-5D-3L items, EQ-VAS scales and the WGO questionnaire. Contact information (email address and names) will be collected at baseline and the email address will be used to send the links for the six later assessments. Every 60 days participants will receive by email a link that will direct them to complete each assessment following the schedule presented in table 1 . Three reminders will be sent at 5-day intervals should the participant not respond. All the data will be collected using formr, ${ }^{18}$ which is a study framework written in $\mathrm{R}^{19}$ providing fully encrypted online form completion and designed to support longitudinal data collection. Formr pseudonymises data using tokens to replace identifiable user data and all connections to https://formr.org/ are encrypted..$^{18}$

\section{Data analysis plan}

The following provides a summary of the a priori data analysis plan. It is recognised that unexpected findings 
or events affecting the study, or the emergence of new analytic methods, might appropriately lead to post hoc analyses. Any such analyses will be clearly marked as such in any reports. The analyses will be divided in two tranches: analyses of baseline data and analyses of change after the termination of data collection.

Baseline analyses will include: (1) the description of demographic characteristics and dependent variable scores (CORE-OM, EQ-5D-3L and EQ-VAS); (2) where bivariate associations between baseline variables (including students/non-student group membership) are statistically significant at $\mathrm{p}<0.01$, the joint relationship of both variables and the dependent variables will be reported with the interaction terms as an exploration of these complexities; (3) for the CORE-OM and EQ-5D-3L internal reliability, factor analysis and convergent validity correlations between the two, and with the EQ-VAS, will be reported, as usual with 95\% CIs and (4) distributions of the dependent variables and WGO scores will be reported as well the association between them.

Change analyses will include: (1) postbaseline patterns of missingness and any apparently non-random relationship between baseline demographic and dependent variables and missingness will be considered in relation to substantive analyses; (2) scores' SD within-subjects and its distribution will be reported for the dependent variables; (3) psychometric explorations will be conducted for the change in scores of the CORE-OM and EQ-5D-3L; (4) the effect of group (student vs non-student) on the scores of the dependent variable will be tested by using multilevel modelling (with group and individuals as levels) and group differences in score changes reported as simple comparison of within-subjects SD of the scores and comparison of highest and lowest intraindividual difference from baseline; (5) afer the student/ non-student comparison the same analyses will be used to explore effects of demographic variables; (6) where cutting points exist for the dependent measures, analyses will describe change on the dichotomised scores, that is, classifications as 'typically clinical or not' will be analysed against group and demographic variables; (7) changes in life events reported on the WGO will be reported and (8) the evidence of a systematic relationship between reported life events and the dependent variable scores within individual over time will be explored graphically and tested using an extension of the cross-lagged panel model introduced in Hamaker et al. ${ }^{20}$ Primary analyses will be by baseline group, but sensitivity analyses will describe impacts of changes of educational status and of attrition. It is anticipated that there will be statistically significant associations of group membership with other demographic variables and between demographic variables. Descriptive exploration of the associations and the interactions between variables and outcome variable scores will be reported.

\section{DISCUSSION}

This period of young adulthood is known to be both turbulent for many and to sow the seeds of success and of problems in later life. ${ }^{2}$ Also, in this life stage serious mental health problems emerge, sometimes with lifelong and transgenerational impacts. ${ }^{3}{ }^{21}$ However, the vast majority of this research has been carried out on student samples and mostly from wealthy countries. ${ }^{12} 22$ This research will complement that body of work by (1) adding information from an emerging country, (2) having equal sized student and non-student samples and (3) by studying change in distress scores and health-related quality of life at seven time points over a year. The results will show to what extent distress changes, whether these changes are marked by individual differences, whether the presence and change of distress relates to student/ non-student status and whether demographic predictors predict distress and changes in distress. This will make it possible to identify trajectories of success and/or distress in people who are going through a life stage that is expected to be full of changes and in which several decisions are made that influence the future lifestyles. This work forms the basis of a programme of studies intended to help create primary and secondary preventative interventions tailored to the needs of this population.

\section{Limitations}

Given the longitudinal nature of the study, the primary limitation is attrition: loss of data over time. We will send several reminders to the participants in each assessment point to mitigate data loss. Sample size must always limit precision of estimation and confidence intervals will be used throughout to indicate likely precision. The samples, from Quito, the capital city of Ecuador, will inevitably not be a random representation of the entire Ecuadorian emerging adult population. The sample demographics will be compared with national and university data to describe possible bias which will be noted carefully when presenting the results. Sensitivity analyses of impacts of attrition and of demographic imbalance will be reported. Also, we are aware that using opportunistic sampling for the non-student group will affect generalisability as will the restriction to groups with access to internet. We will note this limitation when interpreting our results. The psychometric properties of the dependent variables will be explored and reported. The WGO measure uses a participant generated/focused design, not amenable to the psychometric exploration usually applied for fixed item measures. For the analysis of the scores of this measure cross-lagged panel analysis sheds light both on possible substantive relationships between life events and well-being but also a crucial predictive validity test of the measure.

\section{Ethics and dissemination}

Ethical approval for this study has been granted by the Comité de Ética y Bioética (Ethics and Bioethics Committee) of the Universidad de Las Américas, 
Quito-Ecuador (2020-0807). The results of the study will be published in peer-reviewed journals and presented at relevant meetings. Brief reports of these publications will be disseminated using social media to reach the community and private or public organisations interested in emerging adults' population. General results will be sent to participants.

\section{Twitter Clara Paz @clarapaz}

Contributors The study concept and design were conceived by CE, CP and GO-T. Data analysis plan was designed by CE. CP prepared the first draft of the manuscript. All authors read, edited and approved the final version.

Funding This work is supported by the Dirección General de Investigación y Vinculación, Universidad de Las Américas, grant number (PSI.CPE.20.01).

Disclaimer This funding source had no role in the design of this study and will not have any role during analyses, interpretation of the data, or decision to submit results.

Competing interests None declared.

Patient and public involvement Patients and/or the public were involved in the design, or conduct, or reporting, or dissemination plans of this research. Refer to the Methods section for further details.

Patient consent for publication Not applicable.

Provenance and peer review Not commissioned; externally peer reviewed.

Open access This is an open access article distributed in accordance with the Creative Commons Attribution Non Commercial (CC BY-NC 4.0) license, which permits others to distribute, remix, adapt, build upon this work non-commercially, and license their derivative works on different terms, provided the original work is properly cited, appropriate credit is given, any changes made indicated, and the use is non-commercial. See: http://creativecommons.org/licenses/by-nc/4.0/.

ORCID iD

Clara Paz http://orcid.org/0000-0003-1106-9567

\section{REFERENCES}

1 Arnett JJ. Emerging adulthood. 2nd ed. New York, NY, US: Oxford University Press, 2006.

2 Arnett JJ, Žukauskienė R, Sugimura K. The new life stage of emerging adulthood at ages 18-29 years: implications for mental health. Lancet Psychiatry 2014;1:569-76.

3 Patel V, Flisher AJ, Hetrick S, et al. Mental health of young people: a global public-health challenge. Lancet 2007;369:1302-13.

4 Whiteford HA, Ferrari AJ, Degenhardt L, et al. The global burden of mental, neurological and substance use disorders: an analysis from the global burden of disease study 2010. PLoS One 2015;10:e0116820-14.

5 United Nations Educational Scientific and Cultural Organization Institute for Statistics. UIS STAT. gross entry ratio to first tertiary programmes, 2015. Available: http://data.uis.unesco.org/?Reportld= 167 [Accessed 04 Sep 2019].

6 Eisenberg D, Lipson SK, Ceglarek P. College Student Mental Health: The National Landscape. In: Cimini MD, Rivero EM, eds. Promoting Behavioral Health and Reducing Risk among College Students: A Comprehensive Approach. New York, NY: Routledge, 2018: 97-108.

7 Auerbach RP, Mortier P, Bruffaerts R, et al. Who world mental health surveys international college student project: prevalence and distribution of mental disorders. J Abnorm Psychol 2018;127:623-38.

8 Institute of Health Metrics and Evaluation. Global health data exchange. global burden of disease (GBD): deaths, DALYs and prevalence of mental health and substance use disorders, by age and sex, 2016. Available: http://ghdx.healthdata.org/gbd-results-tool [Accessed 04 Sep 2019].

9 Stallman HM. Psychological distress in university students: a comparison with general population data. Aust Psychol 2010;45:249-57.

10 Conley CS, Shapiro JB, Huguenel BM. Navigating the college years: developmental trajectories and gender differences in psychological functioning, cognitive-affective strategies, and social well-being. Emerging Adulthood : 2018.

11 Garett R, Liu S, Young SD. A longitudinal analysis of stress among incoming College freshmen. J Am Coll Health 2017;65:331-8.

12 Eisenberg D, Lipson SK, Ceglarek P. College student mental health: the national landscape. In: Cimini MD, Rivero EM, eds. Promoting behavioral health and reducing risk among college students: a comprehensive approach. New York, NY: Routledge, 2018: 97-108.

13 Evans C, Connell J, Barkham M, et al. Towards a standardised brief outcome measure: psychometric properties and utility of the COREOM. Br J Psychiatry 2002;180:51-60.

14 Trujillo A, Feixas G, Bados A, et al. Psychometric properties of the Spanish version of the Clinical Outcomes in Routine Evaluation Outcome Measure. Neuropsychiatr Dis Treat 2016;12:1457.

$15 \mathrm{Paz}$ C, Mascialino G, Evans C. Exploration of the psychometric properties of the clinical outcomes in routine Evaluation-Outcome measure in Ecuador. BMC Psychol 2020;8:94.

16 van Reenen M, Oppe M. EQ-5D-3L user guide: basic information on how to use the EQ-5D-3L instrument. EuroQol Research Foundation 2015:1-25.

17 Ministerio de Salud Pública del Ecuador - Coordinación General de Desarrollo Estratégico en Salud. Resultados de la encuesta de valoración social de los estados de salud del EQ-5D en la población ecuatoriana. Años de vida ajustado por calidad. (QALY's). Quito, Ecuador: Dirección Nacional de Economía de la Salud, 2019.

18 Arslan RC, Walther MP, Tata CS. formr: a study framework allowing for automated feedback generation and complex longitudinal experience-sampling studies using R. Behav Res Methods 2020;52:376-87.

19 R Core Team. R: a language and environment for statistical computing, 2019.

20 Hamaker EL, Kuiper RM, Grasman RPPP. A critique of the crosslagged panel model. Psychol Methods 2015;20:102-16.

21 Whiteford HA, Ferrari AJ, Degenhardt L, et al. The global burden of mental, neurological and substance use disorders: an analysis from the global burden of disease study 2010. PLoS One 2015;10:e0116820.

22 Auerbach RP, Alonso J, Axinn WG, et al. Mental disorders among college students in the world Health organization world mental health surveys. Psychol Med 2016;46:2955-70. 